\title{
Parameter distribution of crack growth rate in titanium alloy of manned submersible
}

\author{
Chunyang Zhao, Benyang Tu, Xuncheng Tu
}

\begin{abstract}
Based on the Paris and Walker theories of fatigue crack propagation in titanium alloys, a normal distribution model and a two-parameter weibull distribution model were established, and the results under different crack propagation models and different distribution characteristics were compared. The fatigue crack growth model was used to analyze the distribution characteristics of the uncertain material parameters $n, m$ and $C$ under the normal distribution and weibull distribution. Under the condition of crack propagation, the fitting stability of uncertain material parameters under normal distribution is better than weibull distribution with low dispersion.
\end{abstract}

Index Terms - Titanium alloy; Crack propagation; Distribution characteristics; Normal distribution; Weibull distribution

\section{INTRODUCTION}

As a deep-sea scientific research tool, deep-sea manned submersible plays a crucial role in the process of deep-sea development and research. Its pressure-resistant spherical shell plays a decisive role in the whole system as the main pressure structure of technicians and instruments. Considering the working environment, pressure and other factors of deep submersible, titanium alloy is mostly selected as the pressure-resistant shell material. Although titanium alloy has good material properties, its long-term damage and failure are inevitable under the action of periodic and repeated loads. In most cases, structural fatigue analysis adopts the deterministic method. However, no matter the material properties or the load itself, they all have the characteristics of uncertainty, which are the uncertain factors affecting the fatigue life. Against the uncertainty in the process of fatigue crack propagation, the reliability theory is often used to analyze the crack propagation process, but its uncertain material parameters in the process of crack propagation research often has been neglected, and the reliability of the engineering application and theory research is inseparable from the material parameters of accurate statistics for these uncertainty.

In order to solve the influence of uncertain material parameters on the reliability of crack propagation. Some scholars have proposed the method of combining reliability theory with crack growth theory and carried out research on

Chunyang Zhao Postgraduate of Naval Architecture and Ocean En-gineering department of Jiangsu University of Science and Technology,China.+8618796087050

Benyang Tu Postgraduate of Naval Architecture and Ocean En-gineering department of Jiangsu University of Science and Technology,China.+8618260636263

Xuncheng Tu Postgraduate of Naval Architecture and Ocean Engineering department of Jiangsu University of Science and Technology, China. +8618344815748 fatigue crack growth model engineering. Li xiangyang [1] et al., through the improved McEvily model, proposed the fatigue reliability model of titanium alloy manned spherical shell. Based on the statistical characteristics of random variables in the model, the reliability index and failure probability of pressure-resistant spherical shell were obtained by using the important sample method. Deng hongzhou [2] studied the reliability analysis method of structural system, established the structural reliability analysis model, obtained the method of obtaining the main failure mode of structural system fatigue, and discussed the calculation problem of system failure probability. In the establishment of reliability limit state equation, the influence of crack growth model on failure probability must be considered. In this regard, wang yifei et al. [3] changed the power exponent of molecular term of crack growth rate from fixed value to variable, making the model capable of predicting crack growth of different materials. Li xudong [4] obtained a crack growth rate expression based on reliability theory by studying 6151-t6 alloy at different temperatures. These fatigue crack growth models also provide ideas for the selection of models in this paper.

The determination of probability distribution model is the basis of studying the distribution characteristics of uncertain material parameters. According to the randomness and dispersion of crack growth under random load spectrum, liao min [5] applied probabilistic fracture mechanics method to obtain a model describing the statistical characteristics of random crack growth, which can better reflect the statistical characteristics of crack growth. Fan zhiyi [6] obtained the logarithmic normal distribution of the initiation life of low-cycle fatigue crack through the low-cycle fatigue experiment on the notch sample of three-point bending strip of $16 \mathrm{MnR}$ pressure vessel hot-rolled steel. Xie mengying [7] aimed at the uncertainty problem of fatigue Paris crack growth parameters of Q345 steel, based on the fatigue crack growth rate test under constant amplitude load and using seven-point increasing polynomial to sort out and analyze the test data, the optimal distribution type of material parameters was obtained as normal distribution.

Both Paris and Walker models can well predict the stable crack growth stage, and their features of simple form and few parameters make them widely used in engineering and have more practical significance. Based on the fatigue crack growth theory, the Paris and Walker crack growth models were established to obtain uncertain material parameters $\mathrm{C}, \mathrm{n}$ and $\mathrm{m}$. The normal distribution and two-parameter weibull distribution in probability statistics were used to describe their dispersion and distribution characteristics, providing a basis for the reliability study of fatigue crack growth in titanium alloys. 


\section{DETERMINATION OF FATIGUE CRACK GROWTH MODEL PARAMETERS}

The fatigue crack propagation of titanium alloys is usually dispersed and its statistical property is an uncertain variable subject to some probability distribution. In this paper, the fatigue reliability of titanium alloy material is studied by means of fracture mechanics method, and the safety use of the material is evaluated more realistically. Therefore, it is necessary to conduct fatigue crack growth rate test to determine its model parameters, which provides a basis for the study of distribution characteristics.

\section{A. Fatigue crack growth rate test of titanium alloy}

Crack growth rate test is a kind of fatigue crack growth rate test with high cyclic load and low load. Based on the theory of linear elastic fracture mechanics, the fatigue crack growth rate is described by stress intensity factor. The fatigue crack growth rate curves of titanium alloy under different stress ratios were obtained at room temperature.

The samples were processed and prepared according to GB/T 6398-2000 test method for fatigue crack growth rate of metallic materials, $\mathrm{W}=60 \mathrm{~mm}, \mathrm{~B}=25 \mathrm{~mm}, \mathrm{H}=72 \mathrm{~mm}, \mathrm{~S}=75 \mathrm{~mm}$, and the diameter of afterloading hole $\mathrm{D}=12.5 \mathrm{~mm}$. The new titanium alloy was tested with 5 different load ratios, and the samples were shown in Fig. 1.

Fatigue Crack Growth rate Test in jiangsu university of science and technology of titanium alloy structural mechanics laboratory, testing machine and that of extensometer precision meet the national Standard GB/T 6398-2000 "metal material Fatigue Crack Growth rate Test Method" and the United States Standard ASTME649 "Standard Test Method for Measurement of Fatigue Crack Growth Rates" requirement, for the INSTRON testing machine types, Test process as shown in Fig.2, The fracture appearance of CT specimens is shown in Fig.3. The data of fatigue crack growth under different stress ratios are shown in Tab.1

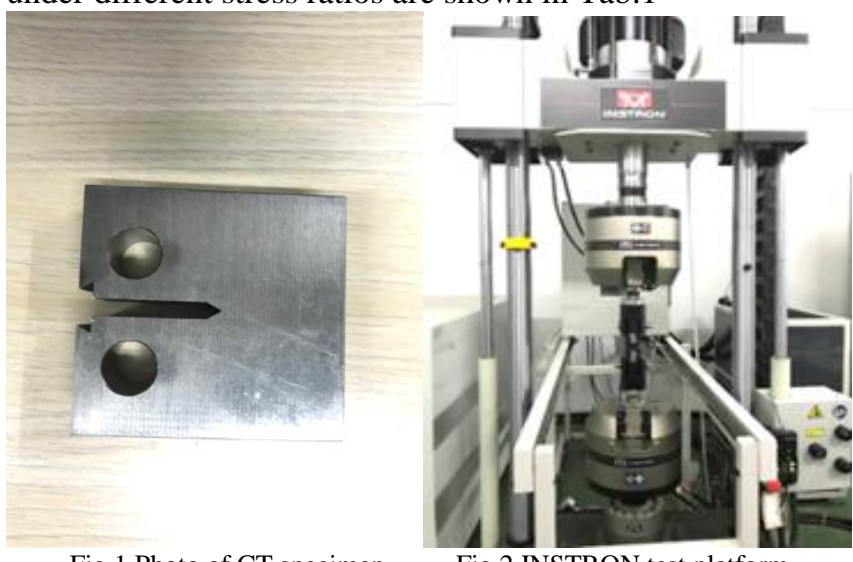

Fig.1 Photo of CT specimen

Fig.2 INSTRON test platform

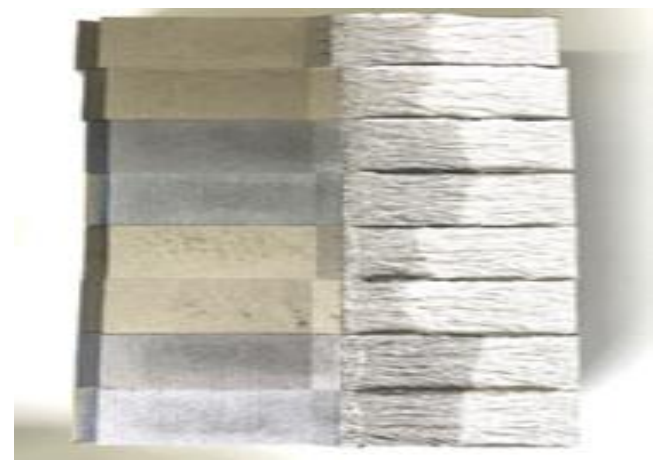

Fig.3 Fracture of CT test fracture
Tab.1 Some test data of crack growth under different load ratios

\begin{tabular}{|c|c|c|c|c|c|c|c|c|}
\hline $\mathrm{R}$ & $\Delta K$ & $d a / d N$ & $\mathrm{R}$ & $\Delta K$ & $d a / d N$ & $\mathrm{R}$ & $\Delta K$ & $d a / d N$ \\
\hline \multirow{5}{*}{0} & $\begin{array}{c}3.26 \mathrm{E} \\
+01\end{array}$ & $\begin{array}{l}5.32 \mathrm{E} \\
-07\end{array}$ & \multirow{5}{*}{0} & $\begin{array}{c}2.70 \mathrm{E} \\
+01\end{array}$ & $\begin{array}{l}7.43 \mathrm{E} \\
-07\end{array}$ & \multirow{5}{*}{1} & $\begin{array}{c}1.95 \mathrm{E} \\
+01\end{array}$ & $\begin{array}{l}1.62 \mathrm{E} \\
-07\end{array}$ \\
\hline & $\begin{array}{c}3.74 \mathrm{E} \\
+01\end{array}$ & $\begin{array}{l}8.94 \mathrm{E} \\
-07\end{array}$ & & $\begin{array}{c}2.91 \mathrm{E} \\
+01\end{array}$ & $\begin{array}{l}7.51 \mathrm{E} \\
-07\end{array}$ & & $\begin{array}{c}2.07 \mathrm{E} \\
+01\end{array}$ & $\begin{array}{l}2.89 \mathrm{E} \\
-07\end{array}$ \\
\hline & $\begin{array}{c}4.02 \mathrm{E} \\
+01\end{array}$ & $\begin{array}{l}1.21 \mathrm{E} \\
-06\end{array}$ & & $\begin{array}{c}3.11 \mathrm{E} \\
+01\end{array}$ & $\begin{array}{l}7.84 \mathrm{E} \\
-07\end{array}$ & & $\begin{array}{c}2.19 \mathrm{E} \\
+01\end{array}$ & $\begin{array}{l}4.42 \mathrm{E} \\
-07\end{array}$ \\
\hline & $\begin{array}{c}4.38 \mathrm{E} \\
+01\end{array}$ & $\begin{array}{l}1.53 \mathrm{E} \\
-06\end{array}$ & & $\begin{array}{c}3.33 \mathrm{E} \\
+01\end{array}$ & $\begin{array}{l}8.34 \mathrm{E} \\
-07\end{array}$ & & $\begin{array}{c}2.34 \mathrm{E} \\
+01\end{array}$ & $\begin{array}{l}4.01 \mathrm{E} \\
-07\end{array}$ \\
\hline & $\begin{array}{c}4.89 \mathrm{E} \\
+01\end{array}$ & $\begin{array}{l}2.32 \mathrm{E} \\
-06\end{array}$ & & $\begin{array}{c}3.60 \mathrm{E} \\
+01\end{array}$ & $\begin{array}{l}9.38 \mathrm{E} \\
-07\end{array}$ & & $\begin{array}{c}2.49 \mathrm{E} \\
+01\end{array}$ & $\begin{array}{l}4.96 \mathrm{E} \\
-07\end{array}$ \\
\hline
\end{tabular}

注 : $d a / d N: \mathrm{m} /$ cycle $; \Delta K: \mathrm{MPa} \sqrt{m}$

\section{B. determination of Paris model parameters}

For the fatigue crack growth model of manned spherical shell, many deterministic fatigue crack growth rate formulas are proposed in fracture mechanics, among which Paris model [8] is expressed as

$$
d a / d N=C(\Delta K)^{n}
$$

The logarithmic linearization is

$$
Y=b_{1}+b_{2} X
$$

Where: $\mathrm{C}$ and $\mathrm{n}$ are material constants, $Y=\lg (d a / d N), X=\lg (\Delta K), b_{1}=\lg C, b_{2}=n$ 。

See Fig.4. The test data $\Delta K$ and $d a / d N$ under different stress ratios are substituted into the Paris formula with double logarithm, and the values of $\mathrm{n}$ and $\mathrm{C}$ can be obtained by using linear regression fitting, as shown in Tab.2.

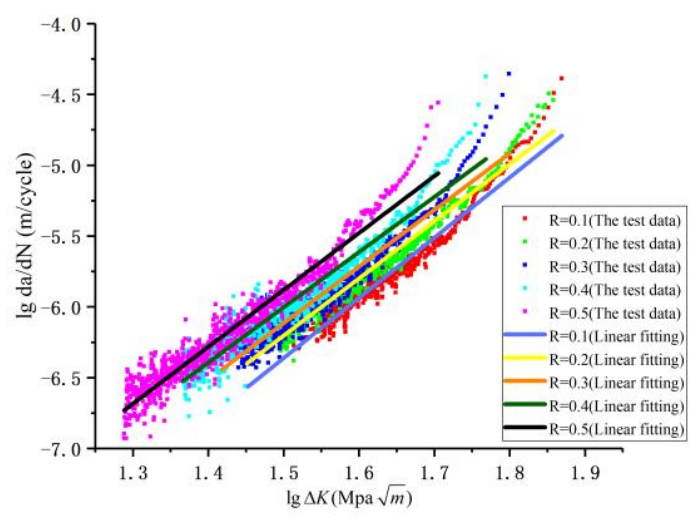

Fig.4 Fatigue crack growth rate parameter fitting

Tab.2 Numerical statistical tables of $\mathrm{n}$ and $\mathrm{C}$ under Paris model

\begin{tabular}{ccccc}
\hline $\mathrm{R}$ & $n$ & $C$ & $\mathrm{Std}$ & $\mathrm{R}-\mathrm{S}$ \\
\hline 0.1 & 4.3 & $1.81 \times 10^{-13}$ & 0.074 & 0.94 \\
0.2 & 4.0 & $5.49 \times 10^{-13}$ & 0.068 & 0.96 \\
0.3 & 3.9 & $7.76 \times 10^{-13}$ & 0.091 & 0.92 \\
0.4 & 3.9 & $1.41 \times 10^{-12}$ & 0.094 & 0.93 \\
0.5 & 3.8 & $1.25 \times 10^{-12}$ & 0.099 & 0.93 \\
\hline
\end{tabular}

Note: r-s represents the correlation coefficient of fitting. The closer $r-s$ is to 1 , the better the curve fitting effect is

\section{C. determination of Walker model parameters}

Walker model [9] is a commonly used mathematical model to describe crack growth rate in engineering applications. It can be applied to crack growth data with different stress ratios, and its formula can be expressed as 


$$
d a / d N=C\left(\Delta K(1-R)^{m-1}\right)^{n}
$$

$M, n$ and $C$ are the material constants.

The logarithmic linearization is

$$
Y=a_{0}+a_{1} x_{1}+a_{2} x_{2}
$$

In the formula : $Y=\lg (d a / d N), X=\lg (\Delta K), a_{0}=\lg C$ , $a_{1}=n, a_{2}=n(m-1)$

Walker model for crack growth rate is a modified model of stress ratio $\mathrm{R}$ according to the fatigue crack growth rate $d a / d N$ And stress intensity factor amplitude $\Delta K$ the crack growth relation fitting curve under different stress ratios, and then the values of $\mathrm{C}, \mathrm{n}$ and $\mathrm{m}$ are obtained. The results are shown in Tab.3

\begin{tabular}{cccccc}
\multicolumn{5}{c}{ Tab.3 numerical statistical tables of $\mathrm{n}, \mathrm{m}$ and C under Walker model } \\
\hline $\mathrm{R}$ & $n$ & $m$ & $C$ & Std & R-S \\
\hline 0.1 & 4.2 & 6.4 & $2.62 \times 10^{-7}$ & 0.074 & 0.94 \\
0.2 & 4.0 & 5.9 & $5.08 \times 10^{-7}$ & 0.068 & 0.96 \\
0.3 & 3.9 & 6.1 & $1.25 \times 10^{-6}$ & 0.091 & 0.93 \\
0.4 & 3.9 & 5.6 & $1.37 \times 10^{-6}$ & 0.094 & 0.93 \\
0.5 & 3.8 & 5.5 & $1.02 \times 10^{-6}$ & 0.992 & 0.92 \\
\hline
\end{tabular}

\section{Fatigue crack growth model fitting analysis}

The linear correlation coefficients of Paris and Walker models are above 0.9 under different load ratios.

1) Paris crack growth model, which represents the overall situation of different stress ratio data, where the material parameter $n$ decreases with the increase of stress ratio, with an average value of 3.98, and $\mathrm{C}$ increases with the increase of stress ratio, with an average value of $8.33 \times 10^{-13}$;

2) the material parameters $n$ and $m$ of Walker crack propagation model decrease with the increase of the stress ratio, with an average value of 3.96 and 5.90 respectively, and $\mathrm{C}$ increases with the increase of the stress ratio, with an average value of $8.82 \times 10^{-7}$ 。

\section{NORMAL DISTRIBUTION MODEL}

\section{A. Linear correlation coefficient test}

If the random variable $\mathrm{x}$ obeys the normal distribution the PTH value obeys the standard normal distribution, and the standard normal deviation $u \_p$ has a linear relationship :

$$
x_{\mathrm{p}}=\mathrm{A}+\mathrm{B} u_{\mathrm{p}}
$$

According to the average rank theory $p=1-i /(n+1)$ substituted its ordinal number $i$ to calculate the estimated value of the transcendental distribution function $u_{i}$, and then calculated the value of the corresponding standard normal distribution variable. Finally, $\left(x_{i}, u_{i}\right)$ was used for linear regression. Where the linear correlation coefficient is defined as:

$$
r=\frac{\sum_{i=1}^{n}\left(x_{i}-\bar{x}\right)\left(y_{i}-\bar{y}\right)}{\sqrt{\sum_{i=1}^{n}\left(x_{i}-\bar{x}\right)^{2} \sum_{i=1}^{n}\left(y_{i}-\bar{y}\right)^{2}}}
$$

Linear regression equation is obtained by least square fitting $x_{p}=A+B u_{p}$, Where $\mathrm{A}$ and $\mathrm{B}$ are:

$$
\begin{aligned}
& A=\frac{1}{n} \sum_{i=1}^{n} x_{i}-\frac{b}{n} \sum_{i=1}^{n} y_{i} \\
& B=\frac{\sum_{i=1}^{n} x_{i} y_{i}-\frac{1}{n}\left(\sum_{i=1}^{n} x_{i}\right)\left(\sum_{i=1}^{n} y_{i}\right)}{\left(\sum_{i=1}^{n} y_{i}^{2}\right)-\frac{1}{n}\left(\sum_{i=1}^{n} y_{i}\right)}
\end{aligned}
$$

\section{B. Parameter estimation of normal distribution}

The normal distribution USES the digital features of point estimation to calculate the mean and variance. As shown in equations (8) and (9), the digital features of sub-samples are used to estimate the digital features of corresponding parent samples.

$$
\begin{aligned}
& E(X)=\bar{X}-\frac{1}{n} \sum_{i=1}^{n} X_{i} \\
& D(X)=S^{2}=\frac{1}{n-1} \sum_{i=1}^{n}\left(x_{i}-\bar{X}\right)
\end{aligned}
$$

$\bar{X}$ and $S^{2}$ are the mean and variance of the words respectively.

\section{WEIBULL DISTRIBUTION MODEL}

\section{A. Linear correlation coefficient test}

Assuming that data $\mathrm{T}$ follows the two-parameter weibull distribution [10], then the distribution function of total $\mathrm{T}$ is:

$$
F(t)=1-e^{-\left(\frac{1}{\eta}\right)^{M}}, t>0
$$

$t_{i}(i=1,2, \ldots, n)$ is the sample from population $\mathrm{T}$, and the data $\left[t_{i}, F\left(t_{i}\right)\right](i=1,2, \ldots, n)$ is substituted into equation (10), and the logarithm is taken for two consecutive times to get:

$$
\begin{aligned}
& \ln \left[\ln \frac{1}{1-F\left(t_{i}\right)}\right]=m \ln t_{i}-m \ln \eta \\
& \text { 令 } y_{i}=\ln \left[\ln \frac{1}{1-F\left(t_{i}\right)}\right], x_{i}=\ln t_{i}, A=-m \ln \eta, B=m
\end{aligned}
$$

Then, equation (10) can be transformed into $y_{i}=A+B x_{i}$, and the regression coefficient can be obtained by least square method.

\section{B. Weibull parameter estimation}

The estimated value of weibull parameters can be obtained from the above correlation coefficients $\mathrm{A}$ and $\mathrm{B}$ :

$$
\begin{aligned}
& \widehat{m}=\widehat{B} \\
& \hat{\eta}=e^{-\frac{\lambda}{m}}
\end{aligned}
$$

\section{MODEL PARAMETER DISTRIBUTION CHARACTERISTICS}

\section{A. Normal distribution characteristics of Paris model parameters}

According to the point estimation method of normal distribution, the mean value and variance of parameters $n$ and $\mathrm{C}$ can be obtained by eq. (8) and (9), and the value range of the normal deviation $u$ [11] can be obtained. The specific values are shown in Tab.4. According to the standard normal deviation $u_{p}$ in the table, the fitting curve of linear regression equation $x_{p}=A+B u_{p}$ of normal distribution of uncertain material parameters $\mathrm{n}$ and $\mathrm{C}$ is shown in Fig .5 and 6 
Tab.4 Values of $\mathrm{n}$ and $\mathrm{C}$ normal skewers under Paris model

\begin{tabular}{cccccccc} 
& Mean & Std & $u_{p 1}$ & $u_{p 2}$ & $u_{p 3}$ & $u_{p 4}$ & $u_{p 5}$ \\
\hline $\mathrm{n}$ & 3.98 & 0.192 & 1.6636 & 0.104 & -0.416 & -0.416 & -0.936 \\
& & & & & & & \\
$\mathrm{C}$ & $8.33 \times 10^{-13}$ & $5.04 \times 10^{-13}$ & -1.294 & -0.56 & -0.114 & 1.1446 & 0.8271 \\
\hline
\end{tabular}

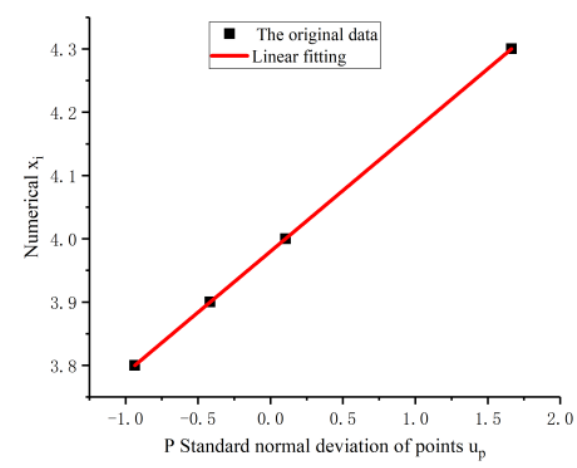

Fig.5 Fitting the normal distribution of parameter $n$

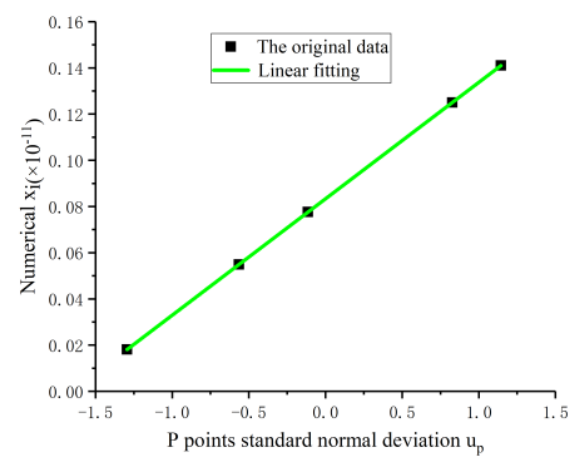

Fig.6 Fitting the normal distribution of parameter C

The uncertain material parameters $\mathrm{n}$ and $\mathrm{C}$ in Paris crack growth model fit well in the standard normal distribution description. In the regression equation $x_{p}=A+B u_{p}$ of normal distribution for uncertain material parameter $\mathrm{n}$, $\mathrm{A}=4.02, \mathrm{~B}=0.1643$, linear correlation coefficient $r=0.99$, and standard deviation is 2.293 . In the regression equation of normal distribution for uncertain material parameter $\mathrm{C}$, $\mathrm{A}=8.332 \times 10^{-13}, \mathrm{~B}=5.039 \times 10^{-13}$, linear correlation coefficient $r=0.99$, and standard deviation is $1.803 \times 10^{-28}$.

\section{B. Weibull distribution characteristics of Paris model parameters}

Crack extension test data fitting of the material parameters in Tab.2 according to the running since the childhood rearrange and $\mathrm{n}, \mathrm{C}$, to calculate the parameters of weibull distribution function [12], $F(t)=\frac{j-0.3}{N+0.4}$, which is a serial number, $\mathrm{n}$ in this as the number of specimens, the available $\mathrm{n}$, $\mathrm{C}$ under weibull distribution of each step calculation results, the corresponding numerical generation $x_{\tilde{i}}$ and $y_{\tilde{i}}$ into type (6), (7), calculate the linear correlation coefficient and standard deviation. The fitting curve of linear regression equation is shown in Fig.7 and 8.

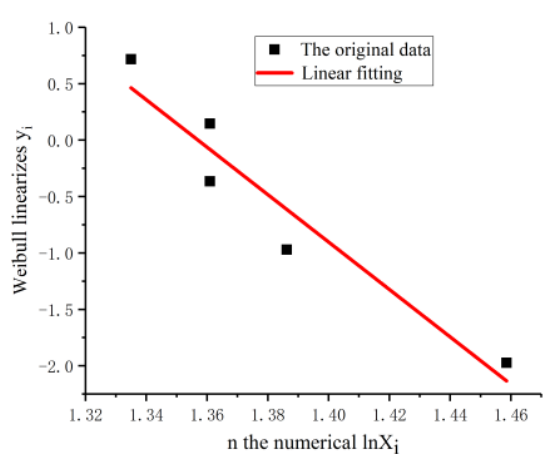

Fig.7 Weibull distribution fitting of parameter $n$

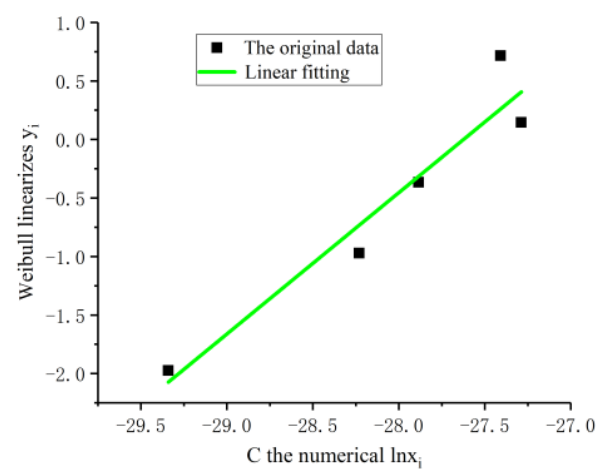

Fig.8 Weibull distribution fitting of parameter C

The coefficients $A=28.51, B=-21.01$, linear correlation coefficient and standard deviation of Paris crack growth model in standard linear regression equation of parameter $n$ under weibull distribution are 0.82 and 0.341 respectively. Using the digital feature method of parameter point estimation, the estimation of shape parameter $\widehat{m}$ and scale parameter $\hat{\eta}$ can be obtained, and $\hat{m}=3.8844, \hat{\eta}=-21.01$. The coefficient $A=33.36, B=1.208$ in the standard linear regression equation of material parameter $C$, the linear correlation coefficient is 0.85 , and the standard deviation is 0.338. Digital features of parameter point estimation method is used to shape parameter can be obtained $\widehat{m}$ and $\hat{\eta}$ scale parameter estimates, $\hat{\eta}=1.0242 \times 10^{-12}, \widehat{m}=1.208$.

Tab.5 Fitting results of material parameter $\mathrm{n}$ under Paris model

\begin{tabular}{ccc}
\hline Distribution type & $\begin{array}{c}\text { Linear correlation } \\
\text { coefficient }\end{array}$ & $\begin{array}{c}\text { Parameter } \\
\text { estimate }\end{array}$ \\
\hline Normal distribution & 0.99 & $\begin{array}{c}\overline{\mathrm{X}}=4.02, \\
\text { Std }=0.1643\end{array}$ \\
Two-parameter & 0.82 & $\hat{\eta}=3.8844$, \\
weibull distribution & $\hat{\mathrm{m}}=-21.01$ \\
\hline
\end{tabular}

Tab.6 Fitting results of material parameter $\mathrm{C}$ under Paris model

\begin{tabular}{ccc}
\hline Distribution type & $\begin{array}{c}\text { Linear } \\
\text { correlation } \\
\text { coefficient }\end{array}$ & Parameter estimate \\
\hline Normal distribution & 0.90 & $\overline{\mathrm{X}}=8.33 \times 10^{-13}$ \\
Two-parameter & & $\mathrm{Std}=5.04 \times 10^{-13}$ \\
weibull distribution & 0.85 & $\hat{\eta}=1.0242 \times 10^{-12}$, \\
\end{tabular}


A.The normal distribution characteristics of Walker model parameters

According to the point estimation method of normal distribution, the mean value and variance of parameters $n, m$ and $\mathrm{C}$ can be obtained from equations (8) and (9), and the value range of the normal deviation $u$ can be obtained. See Tab.7 for specific values

Tab.7 Value of $n, m$ and $C$ normal skewers under Walker model

\begin{tabular}{llllllll}
\hline & Mean & Std & $u_{p 1}$ & $u_{p 2}$ & $u_{p 3}$ & $u_{p 4}$ & $u_{p 5}$ \\
\hline $\mathrm{n}$ & 3.96 & 0.152 & 1.582 & 0.2637 & -0.396 & -0.396 & -1.055 \\
$\mathrm{~m}$ & 5.9 & 0.367 & 1.361 & 0 & 0.5443 & -0.817 & -1.089 \\
& $8.82 \mathrm{x}$ & $4.788 \mathrm{x}$ & & & & & \\
$\mathrm{C}$ & $10^{-7}$ & $10^{-7}$ & -1.295 & -0.781 & 0.7686 & 1.0193 & 0.2882 \\
\hline
\end{tabular}

Fitting curves of normal distribution linear regression equation of uncertain material parameters $n, m$ and $C$ can be obtained from standard normal deviation $u \_p$ in Tab.7, as shown in Fig.9, 10 and 11

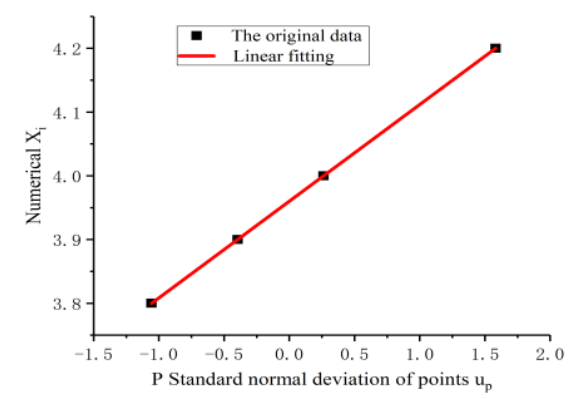

Fig.9 Fitting the normal distribution of parameter $n$

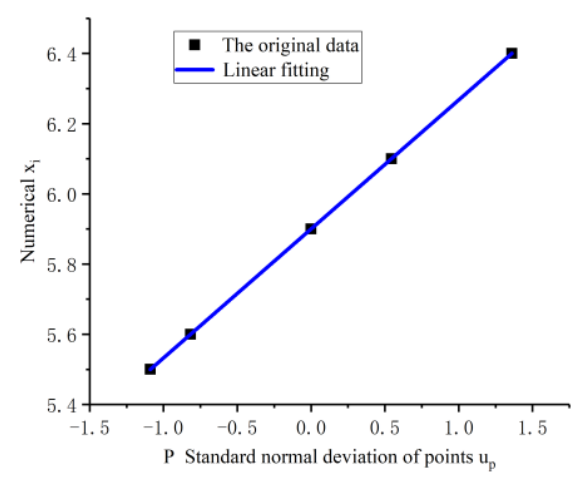

Fig.10 Fitting the normal distribution of parameter $\mathrm{m}$

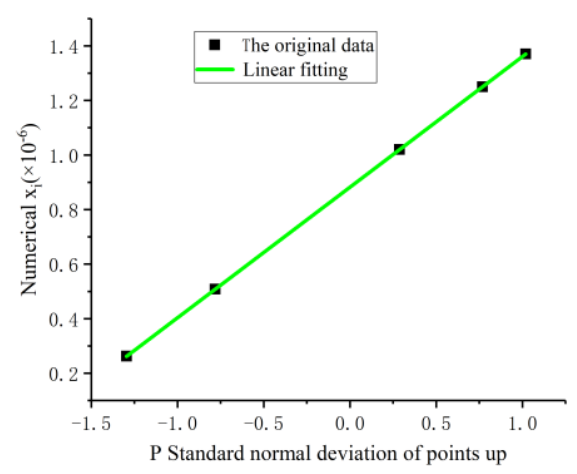

Fig.11 Fitting the normal distribution of parameter $\mathrm{C}$
In the regression equation $x_{p}=A+B u_{p}$ of normal distribution of uncertain material parameter $\mathrm{n}$ in Walker crack growth model, $A=3.96, B=0.1517$, linear correlation coefficient $r=0.97$, standard deviation $=8.504 \times 10^{-16}$. In the regression equation $x_{p}=A+B u_{p}$ of normal distribution of uncertain material parameter $\mathrm{m}, A=5.92, B=0.3671$, linear correlation coefficient $r=0.97$, standard deviation $=$ $1.147 \times 10^{-15}$; In the regression equation $x_{p}=A+B u_{p}$ of normal distribution of uncertain material parameter $\mathrm{C}, A$ $=8.82 \times 10^{-7}, B=4.788 \times 10^{-7}$, linear correlation coefficient $r=0.99$, standard deviation $=3.768 \times 10^{-22}$.

\section{B.Weibull distribution characteristics of Walker model parameters}

Crack extension test data fitting of the $\mathrm{n}, \mathrm{m}, \mathrm{C}$ in Tab. 3 to calculate the parameters of weibull distribution function, $F(t)=\frac{j-0.3}{N+0.4}$, with $j$ is a serial number, $\mathrm{n}$ in this as the number of specimens, the available $\mathrm{n}, \mathrm{m}, \mathrm{C}$ in weibull distribution under each step of the calculation results, and then according to the standard regression coefficient can be obtained and the linear regression equation and linear correlation coefficient and standard deviation. Linear regression fitting diagram of material parameters $n, m$ and $C$ is shown in Fig.12, 13 and 14.

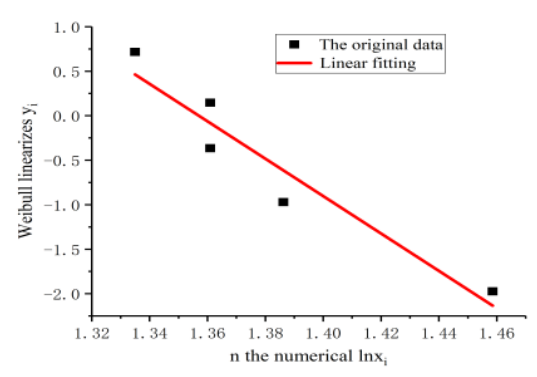

Fig.12 Weibull distribution fitting of $n$

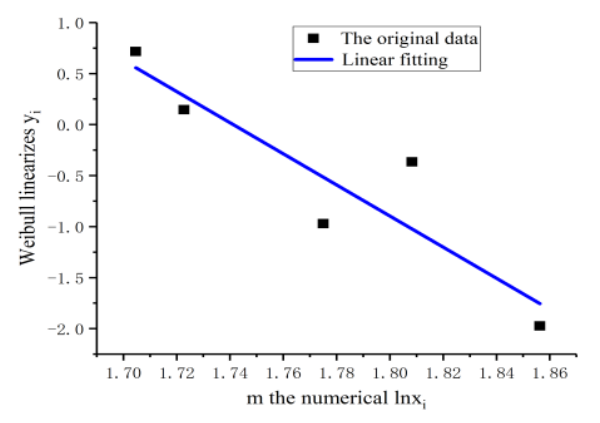

Fig.13 Weibull distribution fitting of $\mathrm{m}$

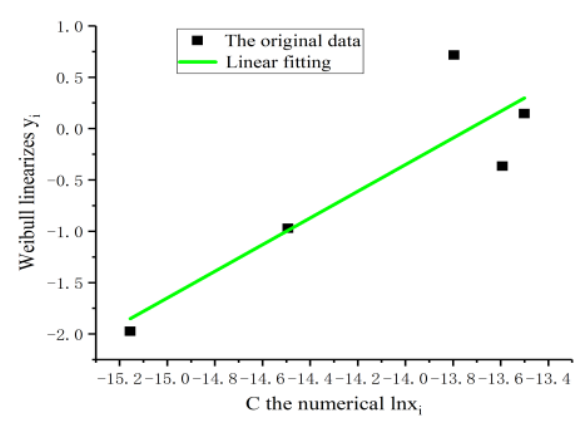

Fig.14 Weibull distribution fitting of $\mathrm{c}$ 
Walker crack propagation model of uncertainty of standard linear regression equation of material parameters $\mathrm{n}$ coefficient $A=36.36, B=-26.79$, the linear correlation coefficient is 0.88 , the standard deviation is 0.255 , using the digital features of parameter point estimation method $\widehat{m}$ available shape parameter and scale parameter $\hat{\eta}$ estimates, get $\hat{\eta}=3.8845$, $\widehat{\mathrm{m}}=26.79$; Material parameter $\mathrm{m}$ standard coefficient of the linear regression equation $\mathrm{A}=28.24, \mathrm{~B}=16.17$, the linear correlation coefficient is 0.82 , the standard deviation is 0.538 , the numerical character of parameter point estimation method can get the shape parameters $\widehat{\mathrm{m}}$ and scale $\hat{\eta}$ estimates, get $\hat{\eta}=$ 5.7341, $\hat{\mathrm{m}}=16.17$; The standard of the linear regression equation coefficient of parameter $\mathrm{C}=17.82, A=17.82$, $B=1.298$, the linear correlation coefficient is 0.69 , the standard deviation is 0.570 , the digital features of parameter point estimation method can get shape parameter $\widehat{m}$ and the scale parameter $\hat{\eta}$ estimates, $\hat{\eta}=1.1, \widehat{m}=1.298$.

The fitting results of distribution characteristics of material parameters $\mathrm{n}, \mathrm{m}$ and $\mathrm{C}$ of titanium alloy in Walker crack growth model are shown in Tab.8, 9and 10 respectively.

Tab.8 Fitting results of material parameter $\mathrm{n}$ under Walker model

\begin{tabular}{|c|c|c|}
\hline Distribution type & $\begin{array}{l}\text { Linear correlation } \\
\text { coefficient }\end{array}$ & Parameter estimate \\
\hline Normal distribution & 0.97 & $\overline{\mathrm{X}}=3.96, \quad$ Std $=0.1517$ \\
\hline $\begin{array}{c}\text { Two-parameter weibull } \\
\text { distribution }\end{array}$ & 0.88 & $\hat{\eta}=3.8845, \widehat{m}=-26.79$ \\
\hline \multicolumn{3}{|c|}{ Tab.9 M fitting results of material parameters under Walker model } \\
\hline Distribution type & $\begin{array}{c}\text { Linear correlation } \\
\text { coefficient }\end{array}$ & Parameter estimate \\
\hline Normal distribution & 0.97 & $\overline{\mathrm{X}}=5.92, \quad$ Std $=0.3421$ \\
\hline $\begin{array}{l}\text { Two-parameter weibull } \\
\text { distribution }\end{array}$ & 0.82 & $\hat{\eta}=5.7341, \quad \hat{m}=-16.17$ \\
\hline \multicolumn{3}{|c|}{ Tab.10 Fitting results of material parameter $\mathrm{C}$ under Walker model } \\
\hline Distribution type & $\begin{array}{l}\text { Linear correlation } \\
\text { coefficient }\end{array}$ & Parameter estimate \\
\hline Normal distribution & 0.99 & $\begin{array}{l}\bar{X}=8.82 \times 10^{-7} \\
\text { Std }=4.7877 \times 10^{-7}\end{array}$ \\
\hline $\begin{array}{l}\text { Two-parameter weibull } \\
\text { distribution }\end{array}$ & 0.69 & $\hat{\eta}=1.1 \times 10^{-6}, \widehat{m}=1.298$ \\
\hline
\end{tabular}

\section{CONCLUSION}

Based on the fatigue crack growth theory of titanium alloy, Paris and Walker calculation models were established in this paper, and the uncertain material parameters under the calculation model were obtained through the crack growth rate test of titanium alloy. The normal distribution and the two-parameter weibull distribution model were used to fit the uncertain material parameters, and the following conclusions were obtained:

1) based on the fatigue crack growth theory and experimental data, the Paris and Walker models were log-processed to obtain uncertain material parameters, and the linear correlation coefficients of these fitting parameters were above 0.9 , which could be used as effective data for characteristic analysis.

2) in Paris calculation model, the linear correlation coefficients of uncertain material parameters are all above 0.9 under normal distribution, and above 0.8 under weible distribution, and there is a linear relationship between $\mathrm{n}$ and C. The standard deviation of normal distribution is obviously smaller than weibull distribution, and its fitting dispersion is less.

3) in Walker calculation model, uncertain material parameter $\mathrm{C}$ shows a great dispersion in the statistical law under weibull distribution, and the linear correlation coefficient of parameter $n$ under both distributions is higher than $\mathrm{m}$ and $\mathrm{C}$. When $\mathrm{n}$ is normally distributed, the distribution of parameters $\mathrm{m}$ and $\mathrm{C}$ should be determined according to the correlation, and the distribution characteristics can also be described with priority to the normal distribution.

\section{REFERENCES}

[1] Li xiangyang, cui weicheng, zhang wenming. Reliability analysis of fatigue life of titanium alloy manned spherical shell [J]. Ship mechanics, 2006, 10(2): 82-86.

[2] Journal of tongji university: natural science edition, 1996, (6): 17-22.

[3] Wang yifei, wang yanwu, wu xiaoyuan, et al. Study on the relationship between threshold value of effective stress intensity factor range and load ratio [J]. Ship mechanics, 2008, 12(3): 440-453.

[4]Li xudong, zhang lianfeng, zhu wufeng, et al. Reliability evaluation of high-temperature low-cycle fatigue crack propagation in aluminum alloy [J]. Equipment environmental engineering, 2013(5).

[5]Liao m, Yang q x. statistical characteristics of crack growth under random load spectrum $[\mathrm{J}]$. Journal of northwest polytechnic university, 1993(3):275-281.

[6]Fan zhiyi. Study on initiation life and probability statistical model of low cycle fatigue crack in 16MnR steel [D]. Southeast university, 2004.

[7]Xie mengying, an zongwen, qin haoxing, et al. Statistical distribution of parameters in Paris formula of steel fatigue crack growth [J]. Machinery manufacturing, 2016, 54(5): 23-27.

[8]Ni xianggui, li xinliang, wang xiuxi. General modification and application of Paris formula for fatigue crack growth law [J]. Pressure vessel, 2006, 23(12):8-15.

[9] Shangguan xiaofeng, fu xiaoqi. Walker formula of TC4 titanium alloy fatigue crack growth $[\mathrm{J}]$. Journal of xi 'an university of technology, 2012, 32(2): 127-130.

[10] Liu guojun, Chen jingpeng. Application of weibull distribution in life analysis [J]. Journal of equipment college, 2003, 14(6): 65-67.

[11] Liu yuan, lu yunbing, huang jing. Statistical correlation of material constants in fatigue crack growth formula and prediction of fatigue growth life $[\mathrm{J}]$. Journal of wuhan university of technology (traffic science and engineering edition), 2004, 28(6).

[12] Liu jiangong, zhang wei, lu yun, et al. Fatigue life analysis of leaf spring based on weibull distribution [J]. Automotive technology and materials, 2017, (10): 40-42.

Chunyang Zhao Postgraduate of Naval Architecture and Ocean En-gineering department of Jiangsu University of Science and Technology,China.+8618796087050

Benyang Tu Postgraduate of Naval Architecture and Ocean En-gineering department of Jiangsu University of Science and Technology,China.+8618260636263

Xuncheng Tu Postgraduate of Naval Architecture and Ocean Engineering department of Jiangsu University of Science and Technology, China. +8618344815748 